LA-UR-

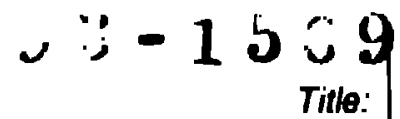

Author(s):

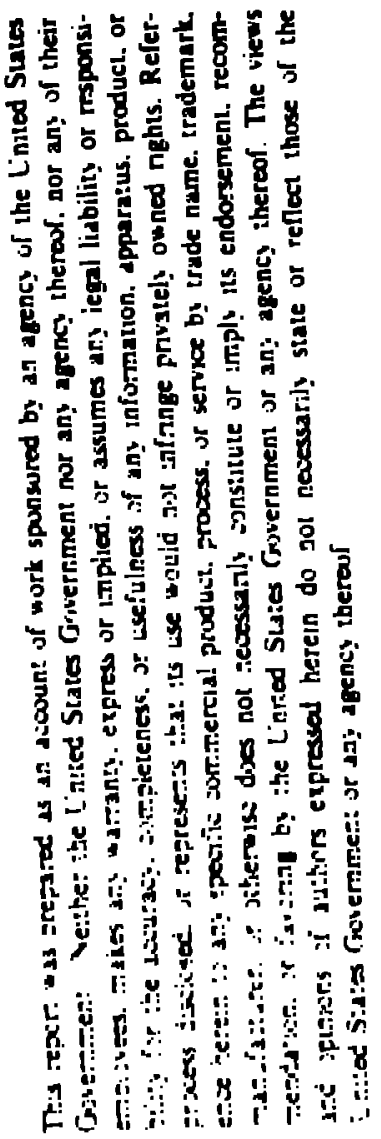

THERMODYNAMICS OF COMPUTATION AND INFORMATION DISTANCE

Charles H. Bennett

Peter Cach

Mtng T.t

Pitul M. B. Vitanyt

Wojelech H. 7.urek, T-6
Submitted to:

Symposium on Theory of Computention (stroc)

25th AcM Lonf., San Dlepo, CA, Jime 1-11, 1993

\section{Los Alamos} NAIIUNAI IAHCHAIU\|Y
$1 / 1: / 11$

\section{MASTER}
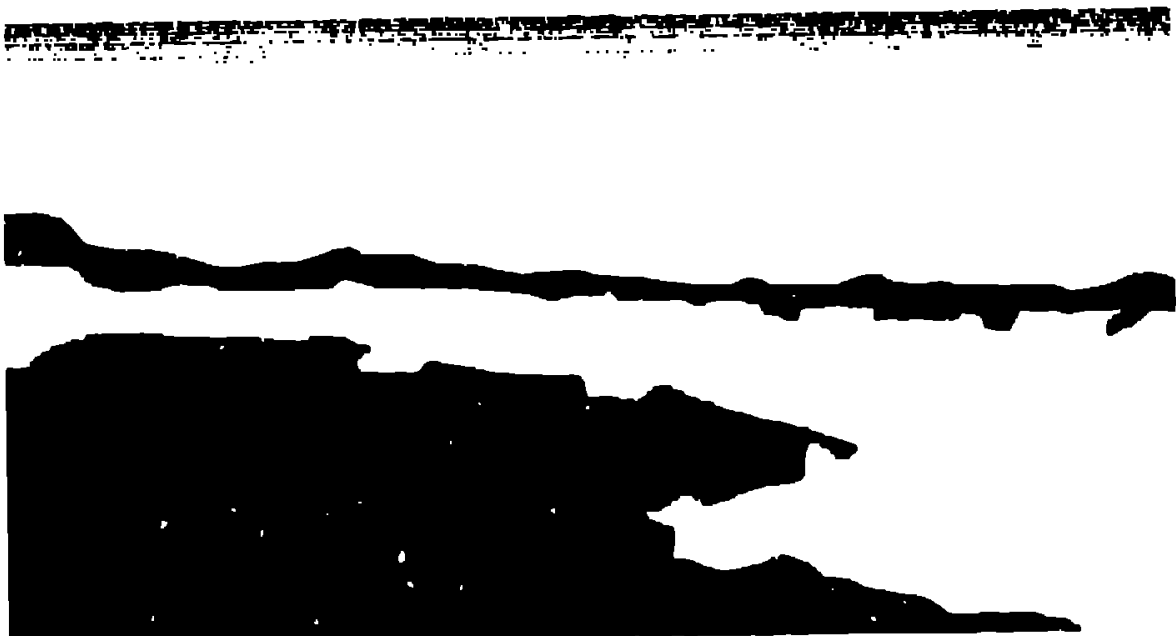

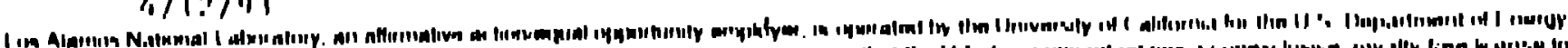

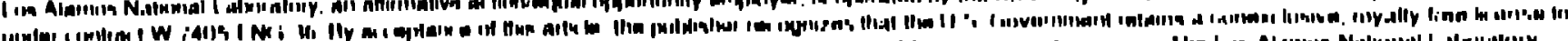

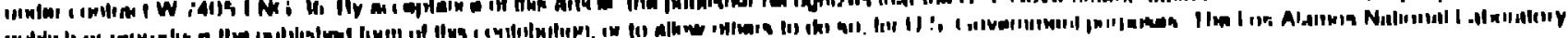

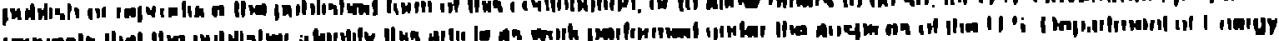

11 


\title{
Thermodynamics of Computation and Information Distance
}

\author{
('harles H. Bennelt \\ Péter Gics \\ Ming $\mathrm{Li}$ \\ Paul M.B. Vitányi \\ Wiojciech H. Zurek
}

March 12, 1993

\begin{abstract}
Applying the tomele of alperithmie information theosy. we compare

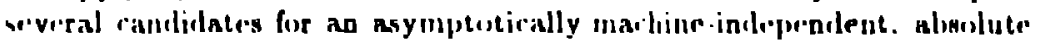

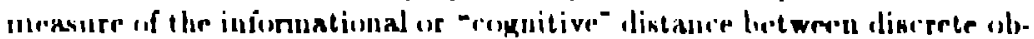

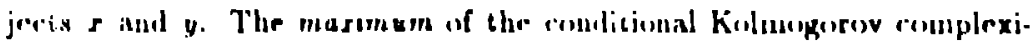
ties max $\left\{K^{-}(y \mid r), K(s \mid y)\right\}$, in shown $t$ lo loptintal, in the sense of being ruinimal withu an alditive roustant among menicompulable, nymmetric,

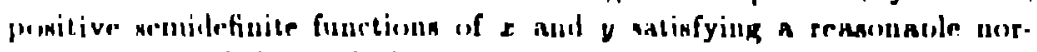

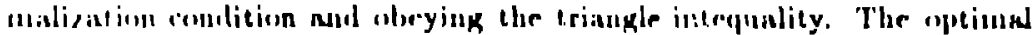
metrie, in turn, differs by at mont an alditure bipivithmie term from the vise of the stuallest program for a univernod renersable computer to trans-

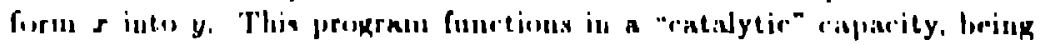
reptioned in the computer before, during. and after the computation. Situ.

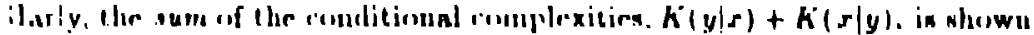

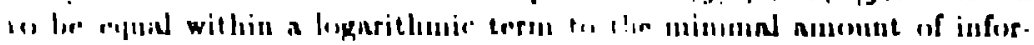

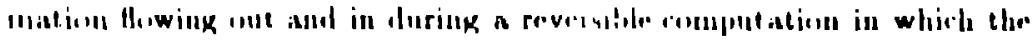

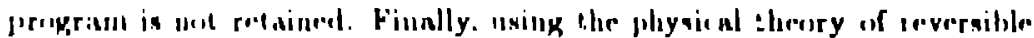

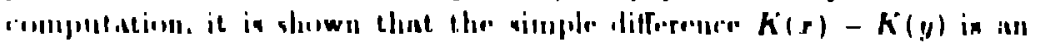

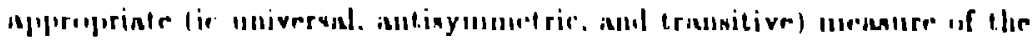

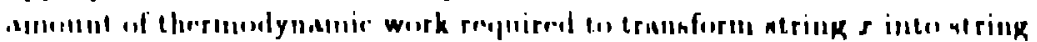

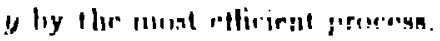

\section{$1 \quad$ Introduction}

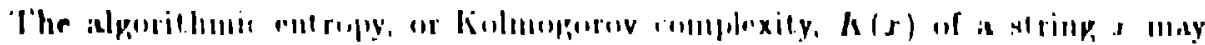

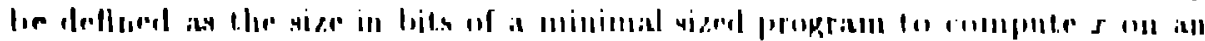

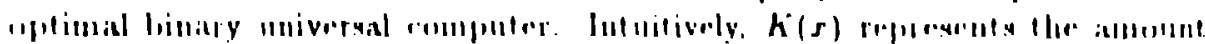

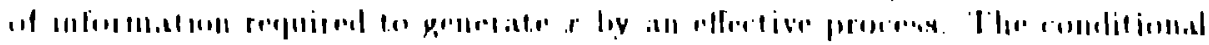

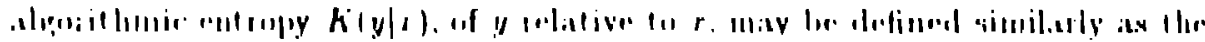

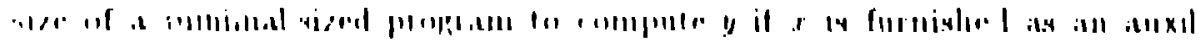

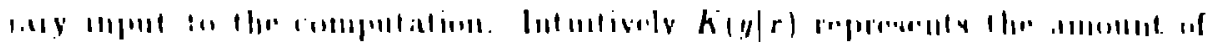




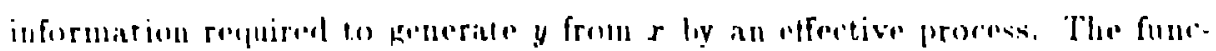

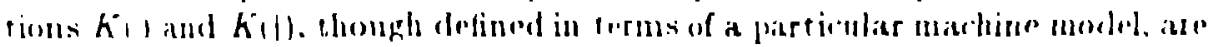

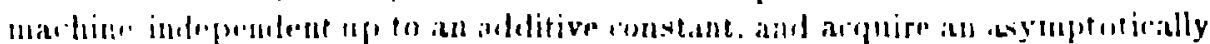

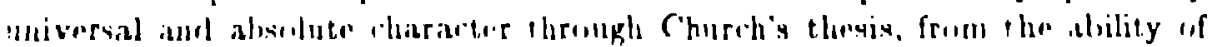
universal mathesest to simulate one another and exerente any efferefive process.

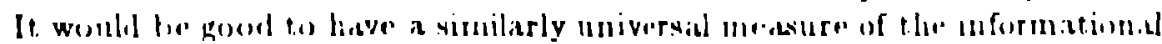

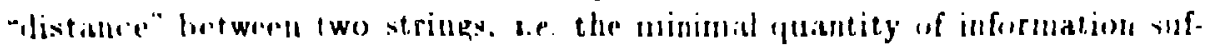

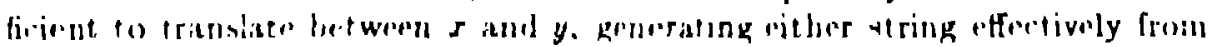
the other. The conditional entropy $K^{*}(y)$ s) itself is of course undulahle for this

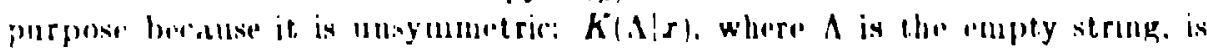

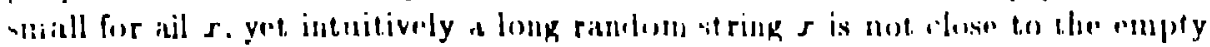
tring.

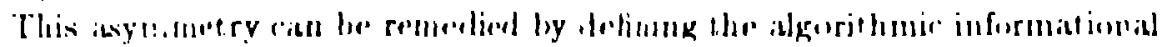

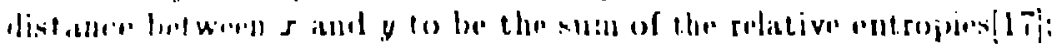

$$
K^{-1}(y \mid s)+K^{-1}(s \mid y) \text {. }
$$

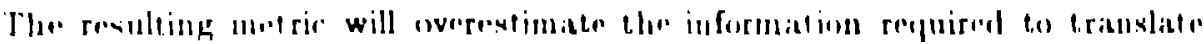

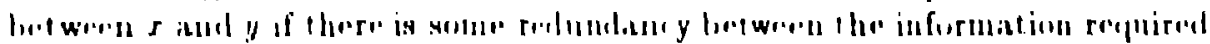

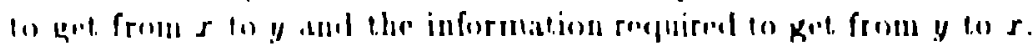

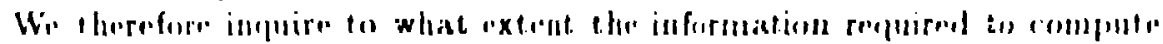

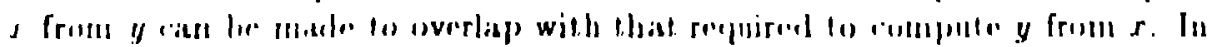

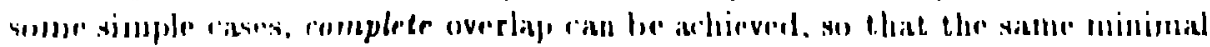

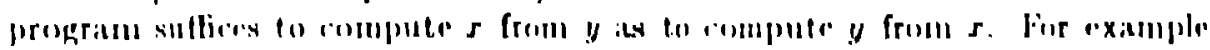

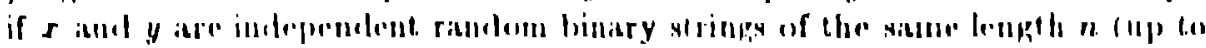

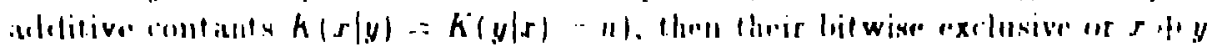

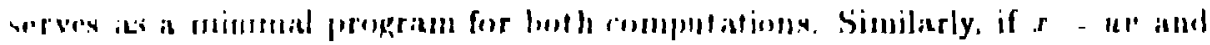

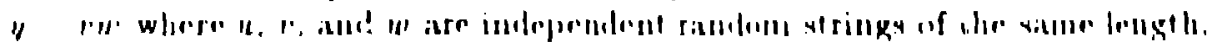

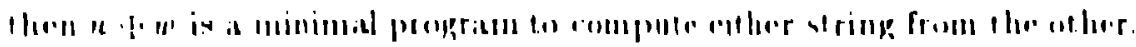

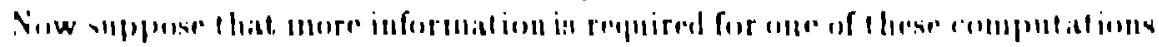
thatl fi,l the whlire, vity.

$$
h(y \mid r) \cdot i r|r| y) \text {. }
$$

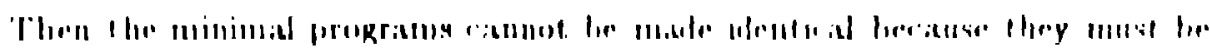

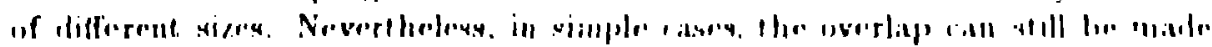

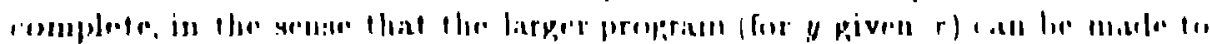

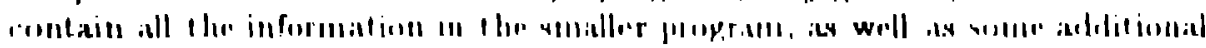

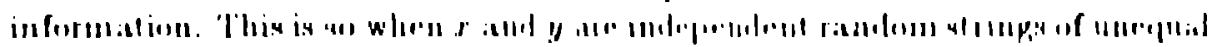

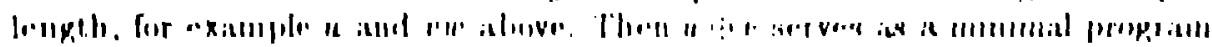

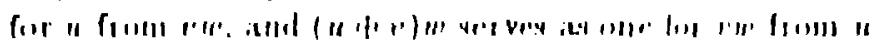

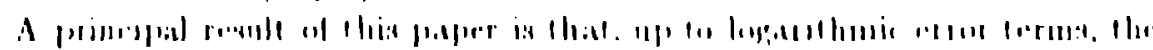

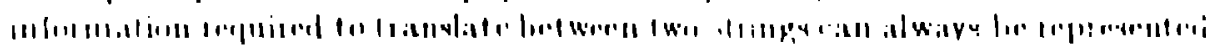

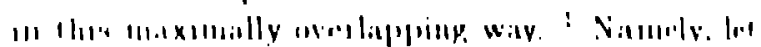

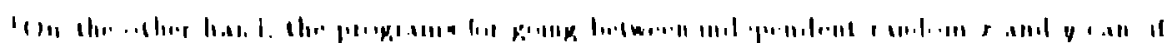




$$
\begin{aligned}
k_{1} & =\boldsymbol{k}(\boldsymbol{s} \mid \boldsymbol{y}) . \\
k_{2} & =\boldsymbol{K}(\boldsymbol{y} \mid \boldsymbol{s}) . \\
l & =k_{2}-k_{1} .
\end{aligned}
$$

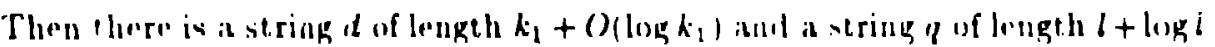
such that d serves as the minimal program both from sq to $y$ atld from $y$ to ry. This meins that the information repuirerl to pisis from $x$ to $y$ is always

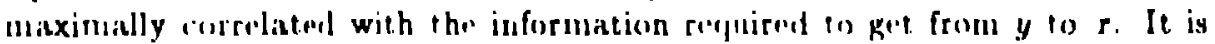
therefore bever the case that a large amenont of infurmation is repuired to get from s to y alld a large but andepentient amount of information is reppuired (1) get fould y to $\mathrm{s}$, flt is very importint here that the time of rompltation

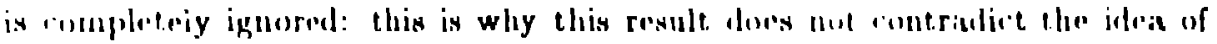
(nil!- way functions.)

The situation is ardugous to the inverso function theorem of moltidimensional analysis. This theorem satys that under certain comelitions, if we have

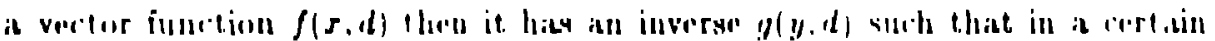
domiain. $f(d, s)=y$ holis if and inly if $g(y, d)=s$. In the function: goving from

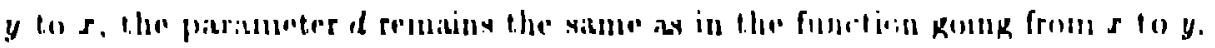

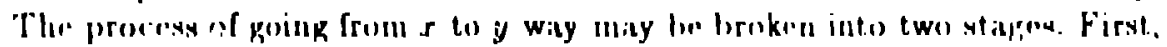

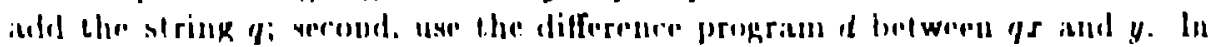

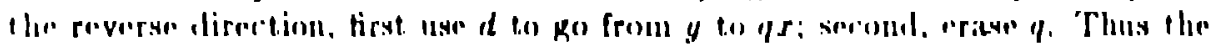

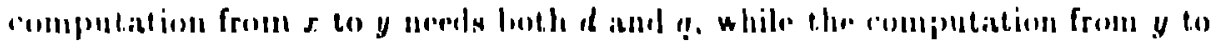

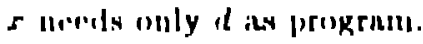

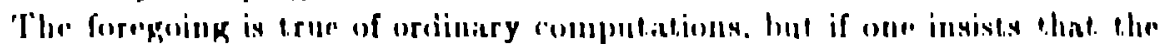
compulation be periormed reversobly. that is by a machine whose hatusition

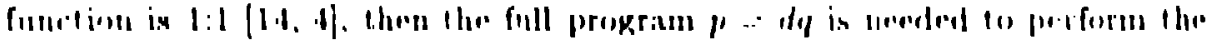

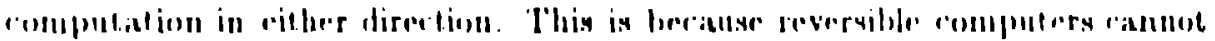

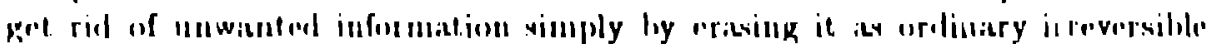

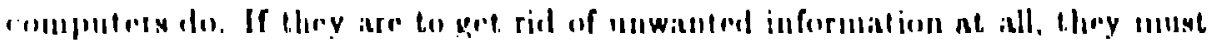

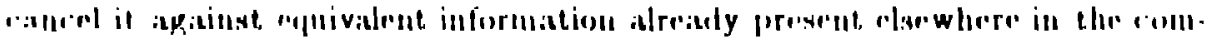

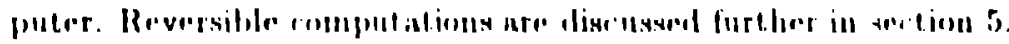

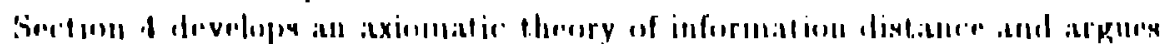
that the function

$$
\therefore(s, y) \quad \ln , L x|k| r \mid y), h(y \mid, r)\}
$$

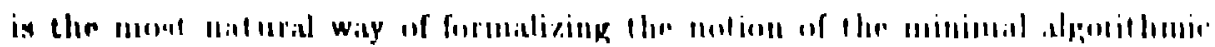

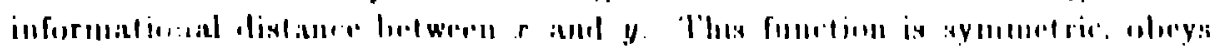

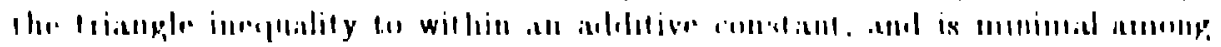

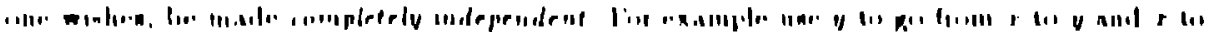

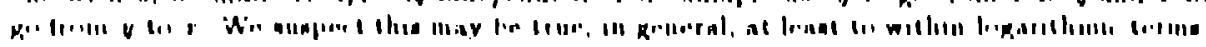


a diss of fumetions satisfying a mormalizatoon ronstraint appropriatoly limiting the number of listinct it rings $y$ within a cribu distanter of any $r$.

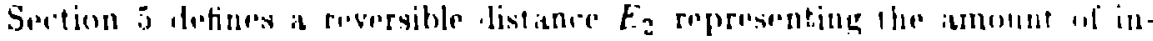

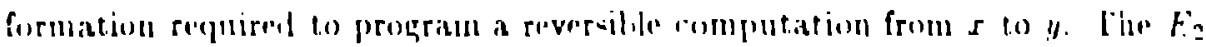

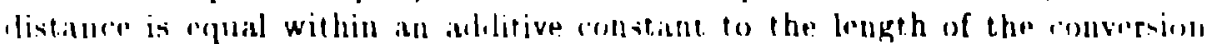

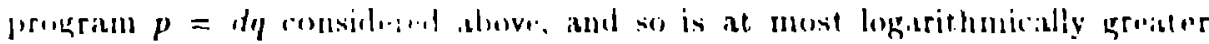

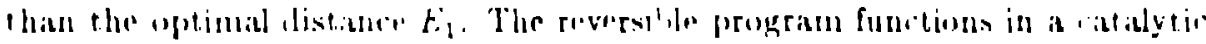

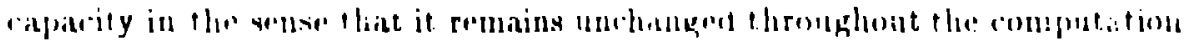

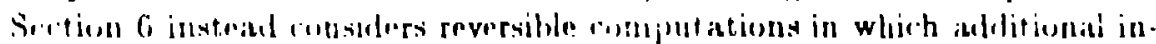

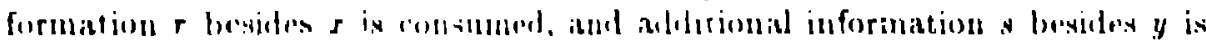

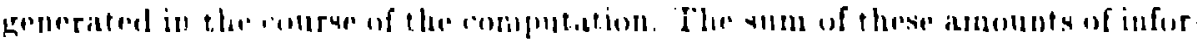

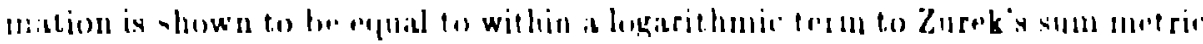
$h(y \mid s)+h(s \mid y)$. Which is typicilly lerger than our proposed optumal metrir

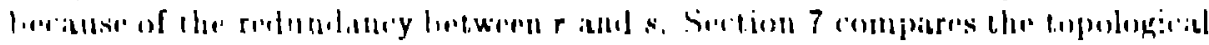
propertice of the ciptimal aul sum metries.

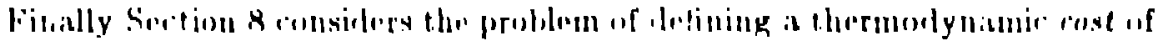

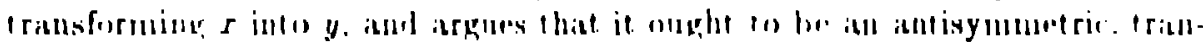

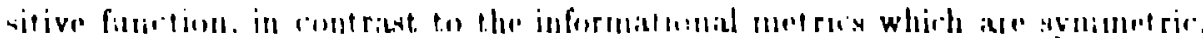

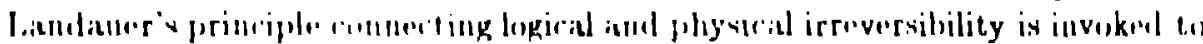

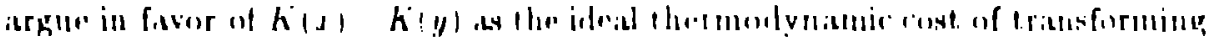
$r$ inl.u $y$.

\section{Known properties of algorithmic entropy}

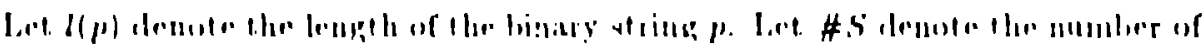
rlomenty of serts.

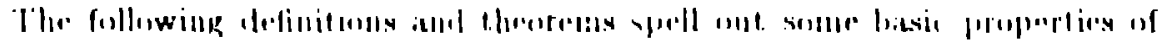
Nil $x$,

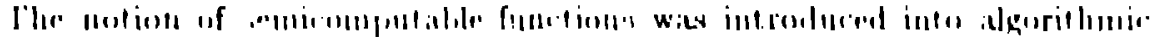

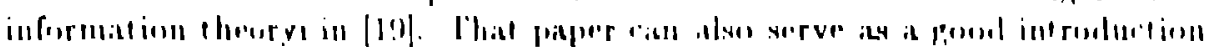

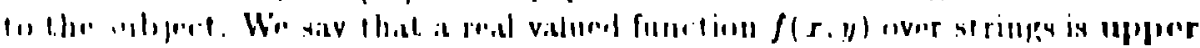

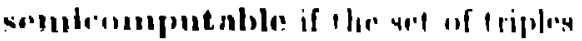

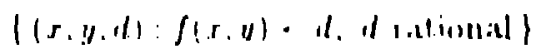

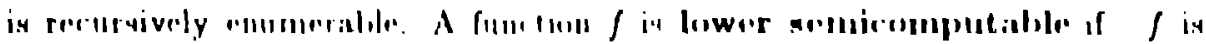

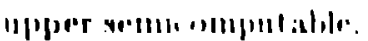

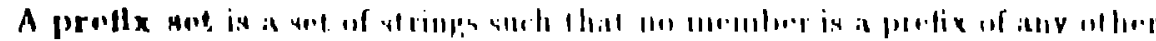

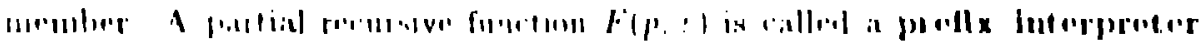

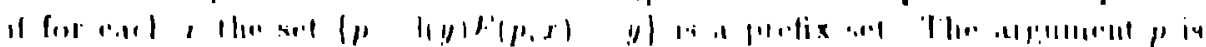

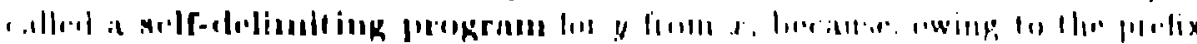
polenty . 11 ', 1 . 
Wi. Intine the conditional algorithmic entropy of $y$ with romition $s$. with respent to the interproter $F$ : as

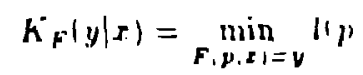

(2.1) Theorem There is a pretix interpreter l? with the property that for all

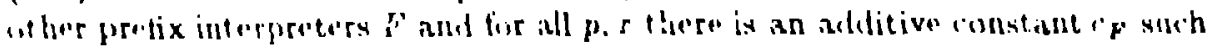
thint

$$
\left.h_{\varphi} \cdot(p) \mid s\right) \leq K_{F}(p, s)+\cdot r F
$$

Sinch a perfix interpreter will be called optimal. Wo fix wuch an $l^{\prime}$ and write

$$
K^{*}(s \mid y)=K_{t}(s \mid y) .
$$

Wre will call $K^{\prime}(s \mid y)$ the algorithmic antropy of $I$ with resperet to $y$.

Fon now an. we will denote hy $\dot{\alpha}$ an inequalisy to wilhin an ablitive ronit allt. and by $\doteq$ the sitnation when both $a_{\text {and }}>$ holul.

\section{(2.2) Thoorem}

(a) $K^{*}(s \mid y)$ is an upper semicomputable function with the property $\sum_{\nu} 2^{k|r| v \mid} \leq 1$

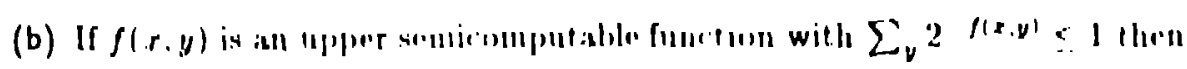
$l i(y \mid r) \therefore f(s, y)$.

(1)

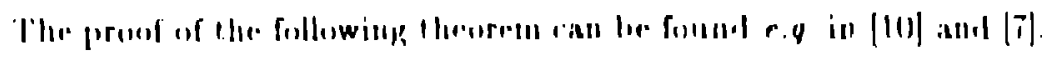

\section{(2.3) Thurorm}

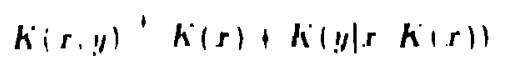

1)

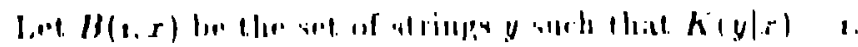

(2.8) 'Thenemull Wr. li.w.

$$
\operatorname{lng}\|\| n+n)^{\prime} n(1, \pi)
$$




\section{Conversion programs}

(3.1) Difference Theorem W'ith the notation of the Introduction. suppose$k_{1} \leq k_{2}$. Then there is a string $p$ of longth $k_{2}+0\left(\log k_{2}\right)$ surch that

$$
l(p .) \cdot r \mid=y \cdot l(p . \mid y)=r .
$$

$\square$

This is equivalent to insiorting that there is a strmg dof longth $k_{2}$ stech that

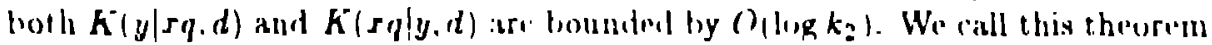
the Difference Theorem since it ibserts the existence of a difference string $p$ that cunverts both ways betwern $r$ and $y$ and at leist. ofle of these conversions is optimal. If $k_{1}=k_{2}$ then the conversion is optimal in both directions.

Proof Let $S$ be the set of all hintry strings, Let .X.Y be twe disjoint set.s

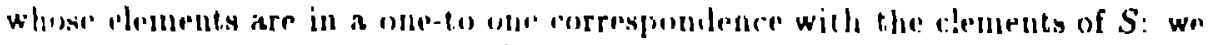
imalil e.g. set $X=\{(s .(1): s \in S\}$ and $Y=\{(s .1): s \in S\}$. Let $G=(X \cup Y, E)$ lw I he following intinite hipartite graph over $X \cup Y$ wich sert of miges of $E$ where

$$
E=\left\{|r, y|: K(s \mid y) \leq k_{11}, K(y \mid s) \leq k_{2}\right\} .
$$

By definition. the maximum degree of the nodes in $X$ is at most $2^{k_{2}+1}$ and in $Y$ is at most $2^{k_{1}+1}$

Two odges are adjacent if they have common enclpoints. A matching is it sert of Inonaljacent relges. Wo can partition $b$ into at most $2^{k_{2}+2}$ matchings $M_{1}, M_{2} \ldots$ If we can do this constructionly we have a program $p$ of length

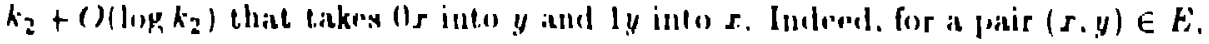

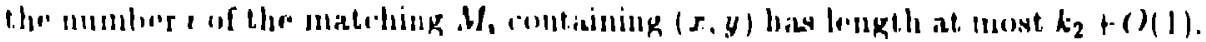
Kunwing e and $s$ gives $y$ whilo knowing a and $y$ givess $s$.

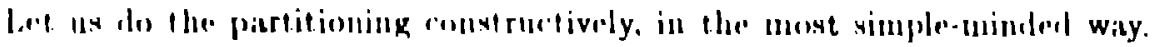

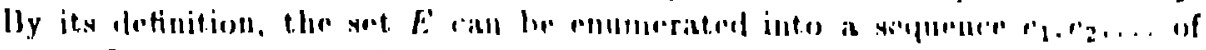

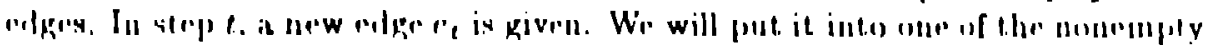

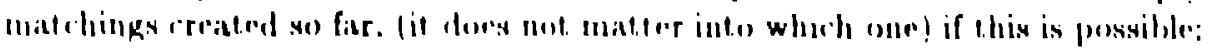

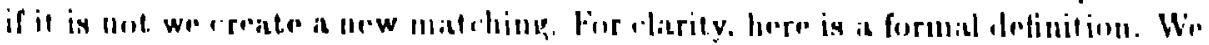

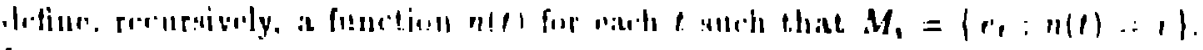
l, 1

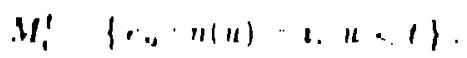

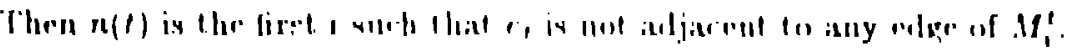

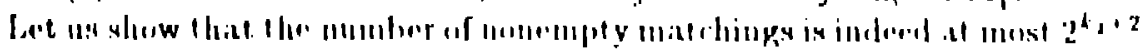

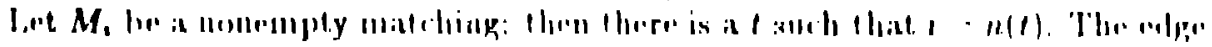

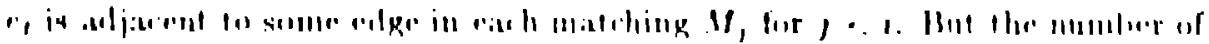

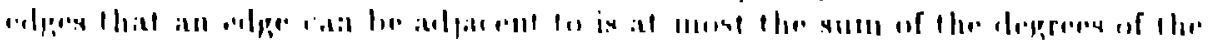

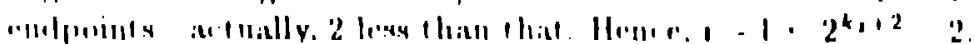

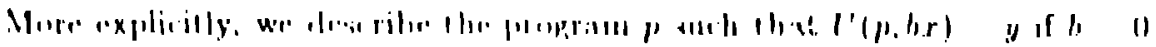

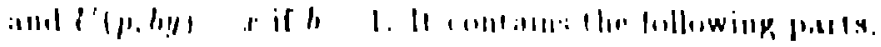


The unutiers kn andi.

Procidure to gemerate the secplence $e_{1}, c_{2} \ldots$

Trocedure to dimeltaneously generate the matching $._{1} . W_{2} \ldots \ldots$

Pincerdure to generate $M_{1}$.

I'roceluse oo find $y$ !sing $x$. $. F_{\text {, if }} b=0$, and to find $x$ using $y . M$, if $b=1$.

(3.2) Excess Theorem Let us luse the above notation. with $l=k_{2}-k_{1}$. There is a binary string $q$ of length $1+0$ (logl) sisch that

$$
\begin{aligned}
& K^{\prime}(y \mid \eta r)=k_{1}+()\left(\log k_{1}\right) . \\
& K^{\prime}(\eta r \mid y)=k_{1}+()\left(\log k_{1}\right) .
\end{aligned}
$$

口

Proof Similarly to the above proof. let the graph $G=(X \cup Y$. E) be now such that

$$
E=\left\{(r \quad z): K(s \mid y) \leq k_{1}\right\} \text {. }
$$

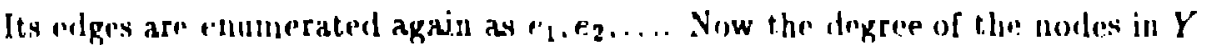
is still $\leq 2^{k_{1}+1}$. Let us detine a new grisph $G^{\prime}=\left(X^{\prime} \cup Y . E^{\prime}\right)$ such that in it, the degree of the degree of alodis in $X^{\prime}$ is also bounded by $2^{k_{1}}$. To do this. we: will simply split the nodes: $Y$ is voon ibt their degrer would rise abluve $2^{k_{1}}$. For each node $s \in X$, let $\left(r, y_{!}\right),\left(s, y_{2}\right) \ldots$ be the natural enumeration (in the

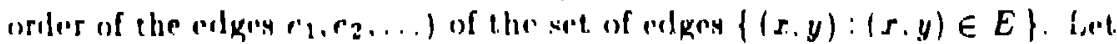

$$
m(n)=\left\lceil n / 2^{h_{1}}\right\rceil \text {. }
$$

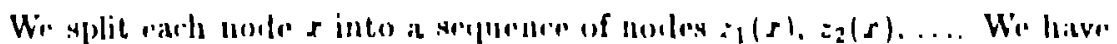

$$
\begin{aligned}
& Y^{\prime}=\left\{: p_{2}|r|: s f X . m=1.2 \ldots\right\} \text {. } \\
& E^{\prime}=\{(2, \ldots, 1)(s), y,: r \in X .1 \leq 1.2 \ldots\} \text {. }
\end{aligned}
$$

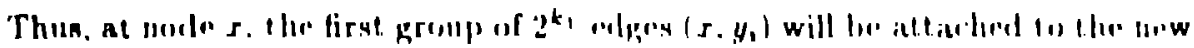

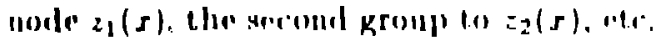

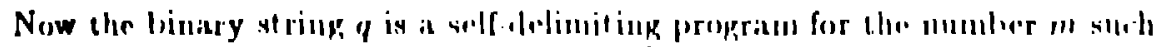

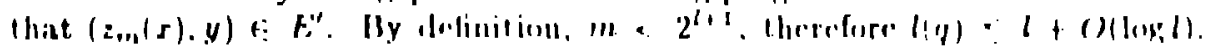

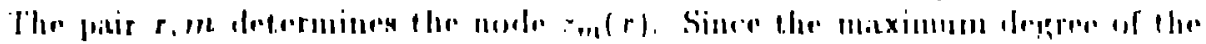

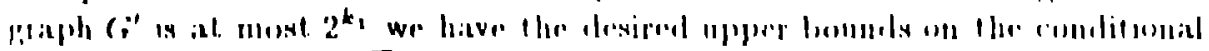

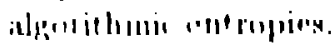




\section{Distance axioms}

Let us identify digitized black-and-white picture with hinary it rings. There are many distances defined for hinary strings. Fur exi mple, the Hamming distance and the Eurlidean distance. Surh distances are iometimes appispriate. For instance. if we take a hinary picture. and rlange a few bics on that pirture. then the rhanged and unchanifod pictures hisw small Hamming ur Euclidean distance. and they lo look smilat. However. this is not always the rase. The positive and negation prints of a photo have the largest possible Hamming and Euclidean distance. yent they lonk smilar in our "you. Also. if we shift a picture wne bit to the right. again the Hamming distance may increace by a lot. but the two pictures remain similar. Many approulies to pattern recognition try to Ietiur pieture cimilarity. Let us show that the distanes $E_{1}$ detined above is, in a sense'. minimal among all riasonable similarity moisiures.

A distance mussure must be nonnegative for all $r \neq y$. symmetric, and satisly the triangle ineguality. This is uot sufticient since a distanco moasure like $D(r . y)=1$ for all $r \neq y$ must be texcluded. For each $s$ and $d$, we want culy tinitoly many elements $y$ at a distance d from $y$. Exactly huw fast we want the distances of the strings $y$ from $r$ to go $t o x$ is not important: it is only a

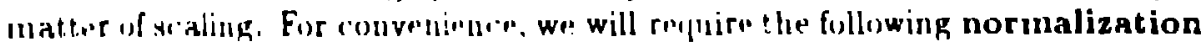
property:

$$
\sum_{y} 2^{D(x \cdot y)}<1
$$

We ronsider only distaneres that are computable in some broad sense. This comblition will not be seen as umluly restrictive. As a marter of fart. only upper somicomprutability of $D(s, y)$ will be reduired. 'This is reisonable: aby we have moer and more time lo process $s$ and $y$ wo may discover urw and

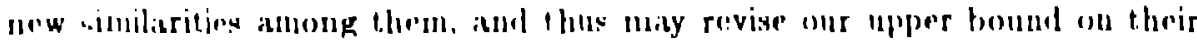
distamer. The apper semicomputability morans exartly that $D(x . y)$ is the limit.

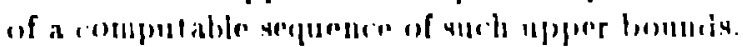

A pormissible distance. $D(r . y)$, is a tot at nonuegative function on the patirs $s, y$ of hinary st, ringes that. is () only if $s=y$. is symmetrie, sattistien the

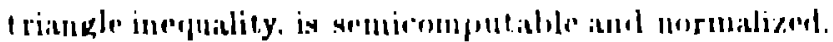

The following thererem shows that $E_{1}$ is. in some sense. the optimal permos.

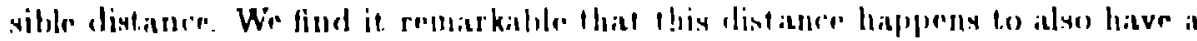

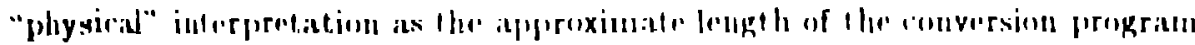

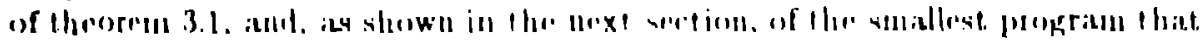
transforms $x$ inter y on a rempililo mathion 
(4.1) Theorem For an appropriare conitant $\therefore \operatorname{let} E(x, y)=E_{1}(r . y)+i$ if $r \geq y$ and o otherwike. Then $E(x, y)$ is a promissible distan a function that is aninimad in the sense that for erery permissible distance funetion $D$ (s,y) we liave.

$$
E(r \cdot y): D(r \cdot y) \text {. }
$$

Proof The nonnegativity and symmetry properties are immediate from lefinition. The addition theorem 2.3 implies that there is a nonmegative integer ronstant $r$ such that

$$
E_{1}(r . z) \leq E_{1}(x, y)+E_{1}(y . z)+r .
$$

Let this , be the one used in the statement of the theorem. then $E(r . y)$ satisties th: triangle inequadity withont an alditive constant.

The normalization property as well as the minimaiity follow from Theorem 2.2 .

\section{Reversible Computations}

Reversible models of computation. in which the transition function is $1: 1$. have beren explored especially in connertion with the guestion of the thernodymanic limits of computalion. Reversibie Turing machines were int roduced by Lecerf]14] ind independently but much later by Berinett [4]: further results concesing them ran be fund in [5]|(3)|(15].

Reversilility of a Turing mildine's transition function can be guarantefed by reppiring elisjointuess of the ranges of the puintugles. just an determinism is guaranterel by repuiring disjoint ness of their donains. To assure that the machine's globid input:ontput relation is also $1: 1$. it is necessary to impose a stamdarel format on the indial and tinal instantanecoss deseriptions, in particular repuiring that all working storage or her than that usel fer the ingut and oulgut.

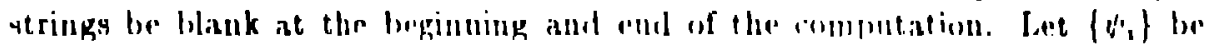
the partial recursive function computed by the ith sult reversible Thring

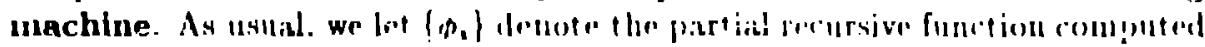
ly the ith ordinary (in general irreversible) Thring, mathine. Among the more important properties of reveruiblo Thing mathines are the following:

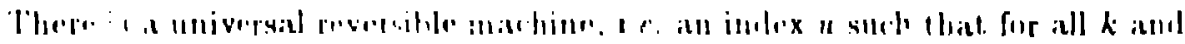

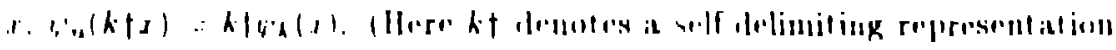

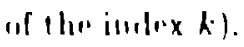


Two irreversible algurithat. ane for impleting $y$ frum $s$ and the ofher it computiug $x$ from $y$. ian be effirintly combined to obtain a reversil l.: .Leorith i for romplatial y from r. Mure lormally. for any two indires : and $J$ onc cin effectively obtain an index $k$ sublh that. for any st rings $t$ and $y$. if $p_{1}(x)=y$ and $b_{3}(y)=r$. $\operatorname{lh}(y+k \mid x)=y$.

From any iudox and may whain an index $k$ sich that 4 'k has the same domain

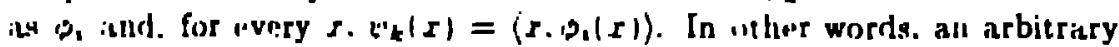
Turing machine ian fre: vimulaterl by a reveruilik one which saves a ingy of the irreversible mathe sy input in order to issiure a golobal 1:1 mapping

The a!use simulation ran le perfurmed rather efficiently. In particular. for ally * $>1$ ) one ran finl a reversilile simulating marhine which runs in time () $T^{1+0}$ ) and space (), Slog $T$ ) compared to the time $T$ and vpare $S$ of the is reversithle machine heing simuaterl.

From iny inlex $九$ one may etferctively obtain an index $k$ surh that if $\phi_{k}$ is $1: 1$. then vit $=\phi_{1}$. The reversible Turing ma-hines $\left\{\psi_{k}\right\}$. therefore. provide a ciindel-numbering of all 1:i partial rerursive functions.

The annection with thermodynamies comes from the fart that in principle: fhe only thermodynamically rostiy computer operations are those that arr logirally irreversible. i. p. operations that map several distine logical states of rhe computer ont a common sureessor. thereby throwing awity information about the computer's previous state [12] [4].[?][5]. The thermulynamics of computation is distussoel further in seretion 8 . Hore we show that the mininal program sise for a reversible computer to transform input $s$ into output $y$ is oqual within in . mlitive constant to the vize of the minimal ronversion string pof theorem 3.1 .

The theory of reversible minimal program sizo is ronveniently deverloped

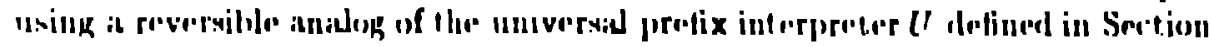
!

A pirtial rencuive function $f(p, s)$ is rallenl a reversihle prefix interproterr if

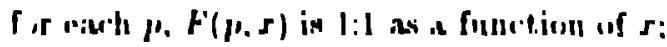

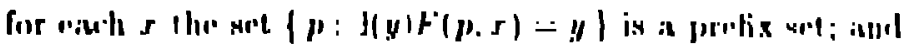

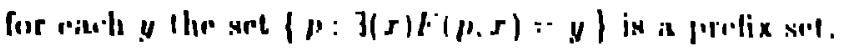

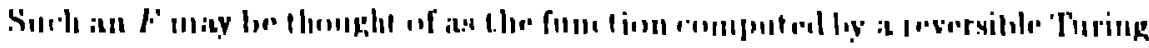

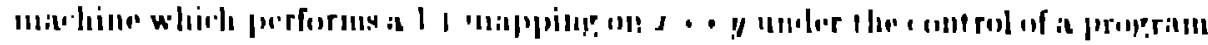

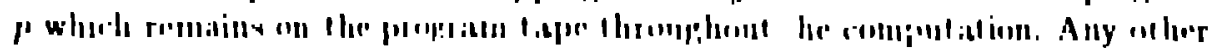

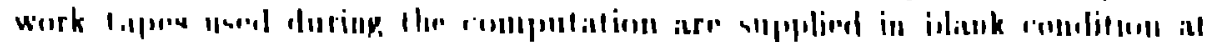

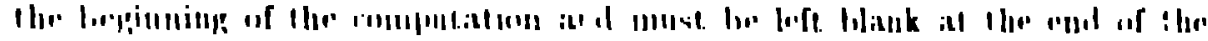


computation. The progeram tapes head begins and emds scauning the leftmost sipuare of the program. which is solf-delimiting loth for forward computations from sach input $\Sigma$ as well ar for hack ward compintations from a ach output $y$.

A universal reversible preflx interpreter $C R$, whose prouram ilap is minimal to within an additive constant. can reislily be shown to exist. and the revergible algorithmic entropy $K R(y \mid r)$ detined as min $\{(l): I R(p . r)=$ $y\}$.

In the Section 3. it was shown that for any strilges $x$ and $y$ there exists a conversion program $p$. of length at most. Iogarithmically greater than $E_{1}(r, y)=$ $\max \{K(y \mid s) . K(s \mid y)\}$. such that $U(p, \| x)=y$ and $C^{\prime}(p, 1 y)=x$. Hert we show that the length of this minimal conversion progran is equal within a const.ont (1) the length of the minimal remersible program for transformistg $x$ into $y$.

\section{(5.1) Theorem}

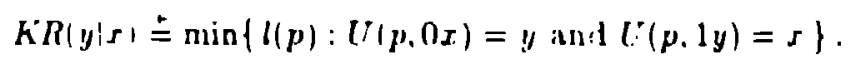

Proof This proof is an example of the generial terhnigun for combining two indeveruble programs, for y from $s$ and for $s$ from $y$. into a vingle reversible

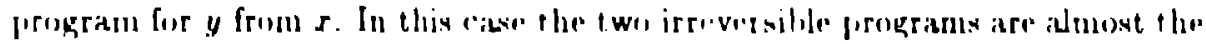
same. siuce by thorom 3.1 the minimal conves won program p is both a progiram for $y$ given $\|_{s}$ imel a program for $s$ given ly. The complutalian procends by

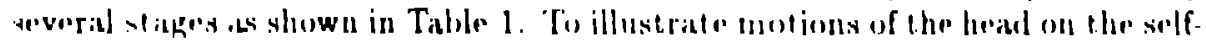

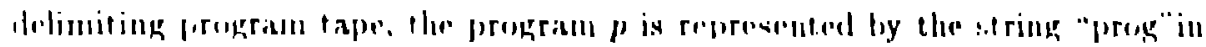

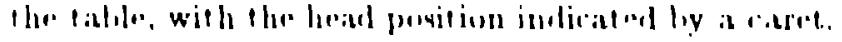

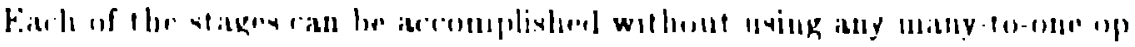

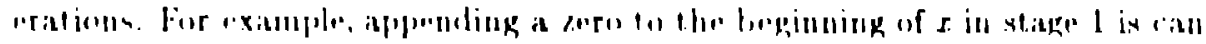

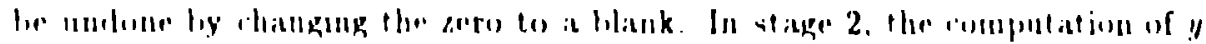

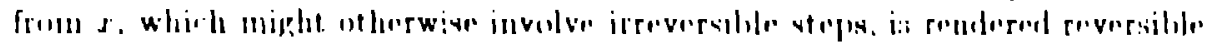

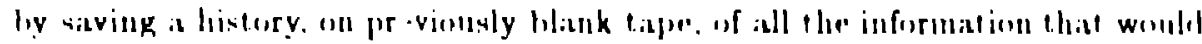

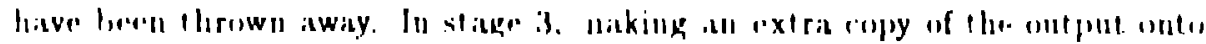

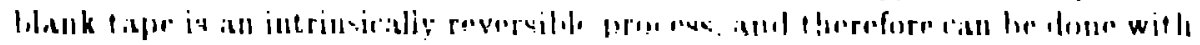

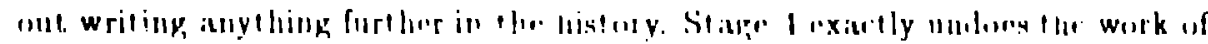

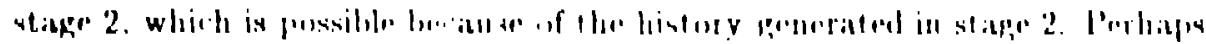

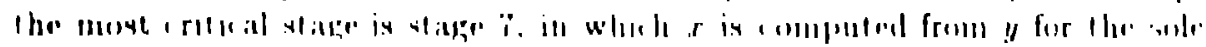

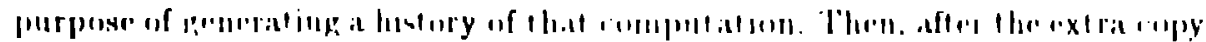

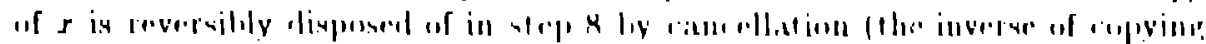

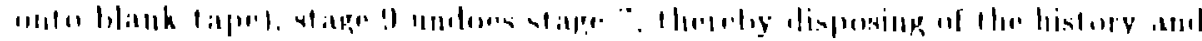

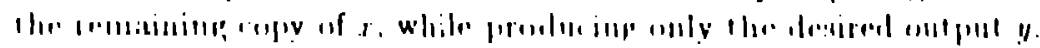

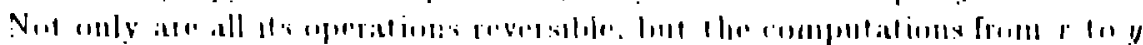

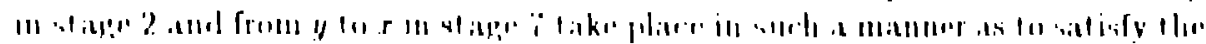

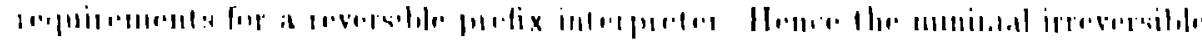




\begin{tabular}{|c|c|c|c|c|}
\hline Stange and Artion & Program Tape: & & Work Tape & \\
\hline 1). Initial $\cdots n$ figuration & prog & $r$ & & \\
\hline 1. Appenu 0 to beginning of $r$ & jirog & $0 x$ & & \\
\hline 2. Compute $y$. saving history & prog & $y$ & $(y \mid x)$-history & \\
\hline 3. Copy y to blank region & pros & $y$ & $(y \mid r)$-history & $y$ \\
\hline 4. Inolo comp of $y$ from $z$ & jirog & () $x$ & & $y$ \\
\hline 5. Remove 0. swap $x$ and $y$ & ṕrog & $y$ & & $\boldsymbol{I}$ \\
\hline 6. Append 1 to $y$ & jrog & $1 y$ & & $\boldsymbol{s}$ \\
\hline i. Compute $s$, saving history & prón & $\boldsymbol{r}$ & $(x \mid y)$-history & $\boldsymbol{x}$ \\
\hline 8. Cancel ixtra $x$ & prog & $r$ & $(s \mid y)$-history & \\
\hline 9. Enolo comp. of $x$ from $y$ & jrog & $1 y$ & & \\
\hline 10. Remuve if from $y$ & jorog & $y$ & & \\
\hline
\end{tabular}

Table 1: Combining irreversible computations of $y$ from $x$ and $x$ from $y$ to arhieve a reversible compulation of $y$ from $s$.

conversion program $p$. with constant modification, can l,a usoul as a reversible progran for l'R to iompute $y$ from $x$.

Conversely, the minimal revervible program for $y$ from $r$, with constant monlification. serves as a program for y from $x$ for the orelinary irreversible prefix

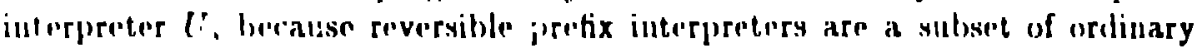
prefix interpreters. This astahlishes the theorem.

Wo define the reversible distance bolwern $r$ ind $y$ :

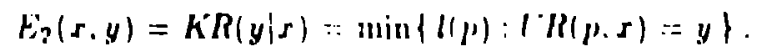

As just proverl, this is within an inditive roustant of the vize of the minimal

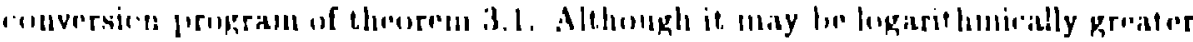

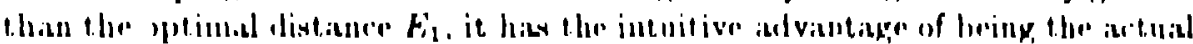
length of a conterete program for piwsing in either dirortion hertwent $s$ and $y$.

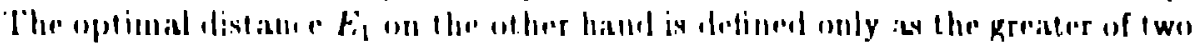

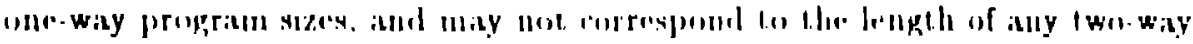
trameliation proprath.

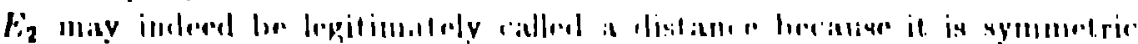

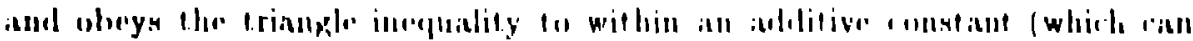

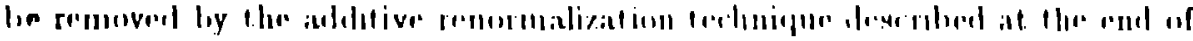
Sircliun (1).

(5.2) Theoren

$$
f(x,:):\{(r, y)+f(y,:)
$$




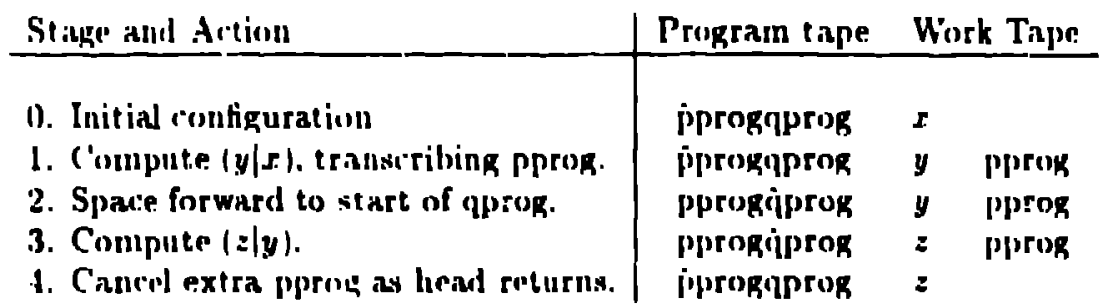

Table 2: Reversilile execusiun of coniatenutoul prograns for $(y \mid s)$ and $(z \mid y)$ (o) pransform $r$ intu $z$.

Proof Wr will show that. given reversiblo l'R programs $p$ and q. for computing $|y| r \mid$ and $(z|y|$ respect $\mid$ vely. a program of the form spm. where s is is countant supervisory routiue, serves to rompute a from $r$ reversibly. Bocalise the programs are sulf-delimiting. no punctuation is nerded brtwern them. If this wero an orelinary irreversilion $[$ (omputation. the concatenated program spy rould] ho rxorufed in an entirely straighteforward manner. firse using $p$ fo go from $s$ (0) 6. Then using y to go from y tos : Ilowever. with reversiblo I:R programs. after "xerentiug p. the head will be locited at the heginning of the program enpe. and

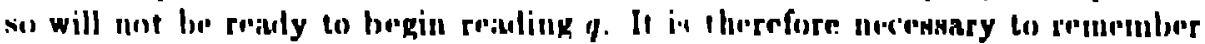

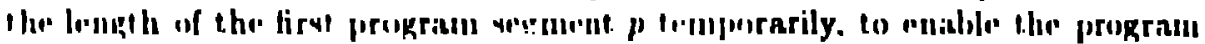

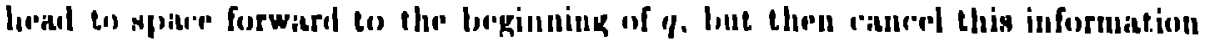

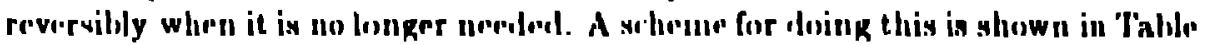

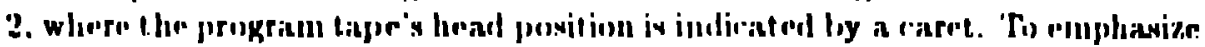

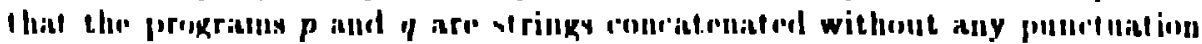

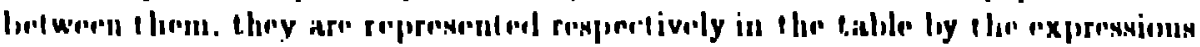

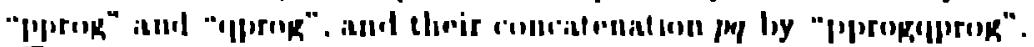

\section{The information flux distance}

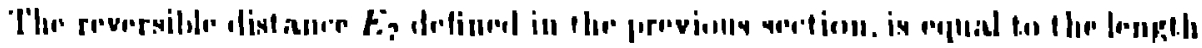

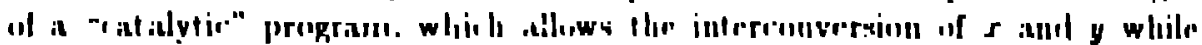

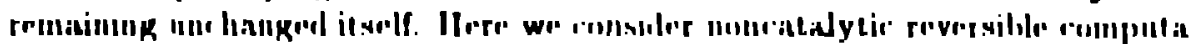

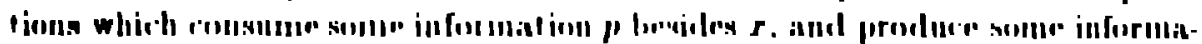

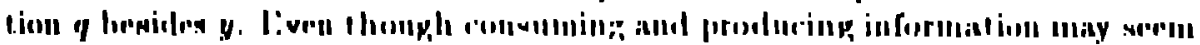

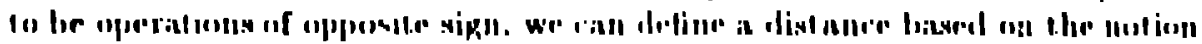

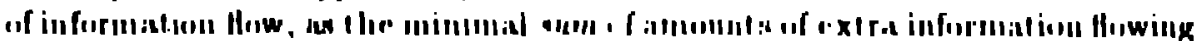

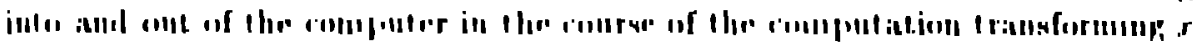
inll' y

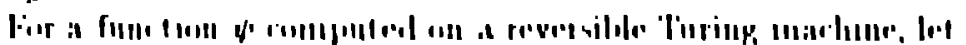

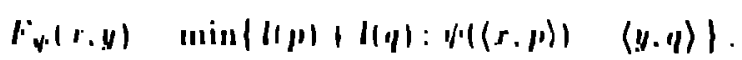


(6.1) Lemma There is a universal (non-self-drlimiting) reversible Turing machine $\psi_{16}$ such that for all functions $\psi$ computed on a reversible Turing machine. we have

$$
E_{\varphi}(x, y) \leq E_{\psi}(x, y)+r_{\psi}
$$

for all $\varepsilon$ and $y$. whree $\psi$ is a constant which depren:ls on $\psi$ but not on $x$ or $y$. $\square$

Proof This is a consoguence of the existence of universal reversible Turing machines(c) soction 5$)[1+] \mid 4]$.

We define the sum distance as

$$
E_{3}(x, y)=E_{v_{-}}(x, y)
$$

(6.2) Theorem

$$
E_{3}(s . y)=K(x \mid y)+K(y \mid s)+O\left(\log E_{3}(s \cdot y)\right) .
$$

Proof Laet ur whow first the lower boumd

$$
F_{3}(r, y) \geq K(y \mid s)+K(s \mid y)
$$

To compite y from $r$ we must be given a program $p$ fo do so to start mit with. By definition.

$$
K(y \mid s) \leq l(p)+()(\log (p)))
$$

The last hem reflecets lhe fate that $p$ is externally delimited, while the mini-

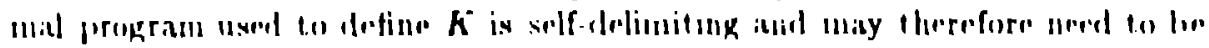
logarithmically longer. ${ }^{2}$

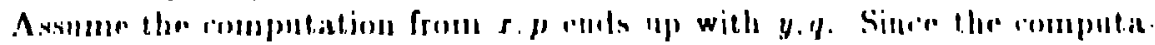
tion is reversible we can compute $s$ from $y . y$. (omsereluently, $h(s \mid y) \subseteq \| y)+$

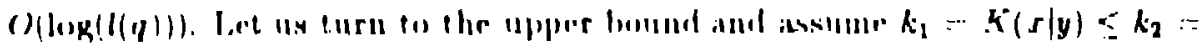
$k(y \mid s)$ vithl $=k_{2}-k_{1}$. Ancording to Theorem 3.2 , there is a st ring y of length

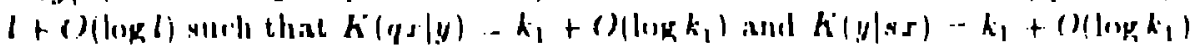

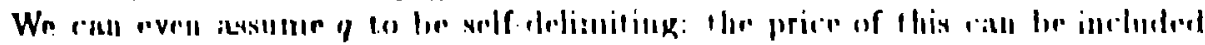

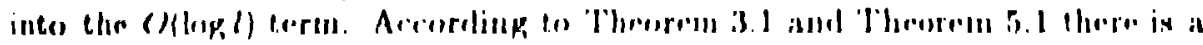

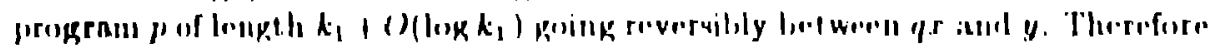

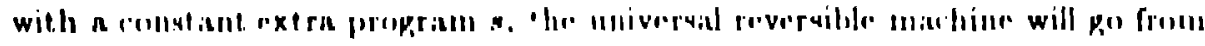

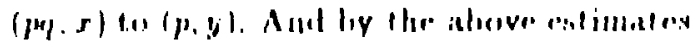

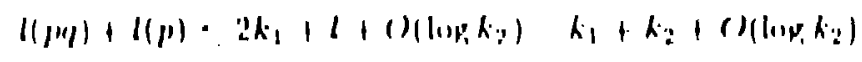

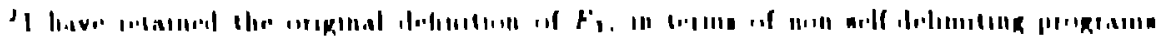

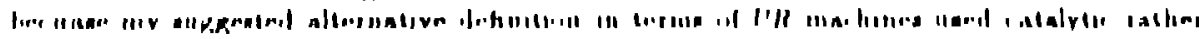

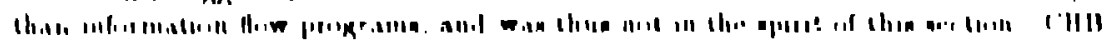


Note that all bits supplied in thre beginning to the computation, apart from input. $r$. as wrll at all bity erizied at the end of the computation, are: rundom bits. This is because we supply and dolete only sluortast prograns. and a shortest. program $p$ satisties $K^{-}(p) \geq l(p)$. that is. it is misximblly random.

The metries we have considered can lie arranged in increating order. Here, the relation $\stackrel{\log }{<}$ means inequality to within an additive (O)log). and $\stackrel{\text { log }}{=}$ means $\stackrel{\log }{<}$ indil $\stackrel{\operatorname{lug}}{>}$.

$$
\begin{aligned}
& \left.E_{1}(r, y)=\max \mid K(y \mid r) \cdot K(s \mid y)\right\} \\
& \stackrel{\operatorname{lng}}{=} E_{2}(s, y)=K R(y \mid r) \doteq \min \left\{l \mid \mu l:(r(p, 1) r)=y \operatorname{and}\left(l^{\prime}(p, \mid y)=r\right\}\right. \\
& \stackrel{\log x}{<} K(r \mid y)+K(y \mid r) \stackrel{\operatorname{lig}}{=} H_{3}(r, y) \\
& \stackrel{\operatorname{lig}}{<} 2 E_{1}(s, y) \text {. }
\end{aligned}
$$

The sum distance $E_{3}$. in other words, an be illywhere betwern the optimum histance $E_{1}$ and twien the optimal distance. The former ocrenes if one of the con-

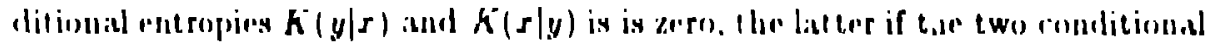
entropiten isre engual.

\section{Dimensional properties}

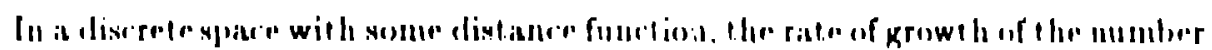

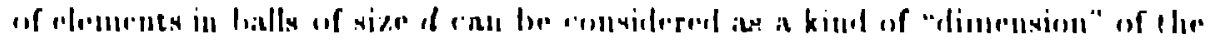

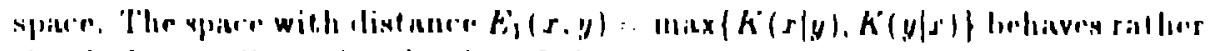
vimply from a dimenuimal porinte of view.

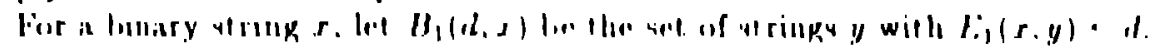

(7.1) Theorem Win have

$$
d \cdot h(d) \cdot|\ln , \#| H_{1}|d, r| \cdot d \quad h(d|, r| .
$$

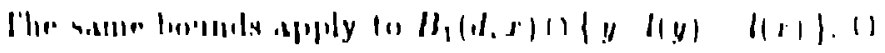

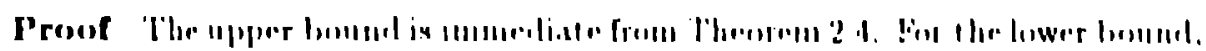

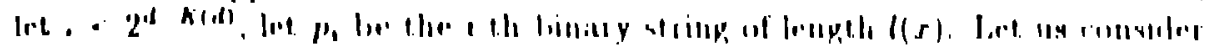

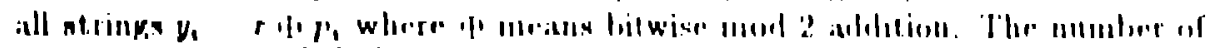

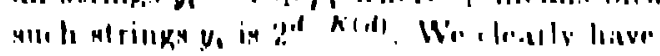

$$
l\left(1, v_{1}\right):(n) ! \cdot 1 .
$$

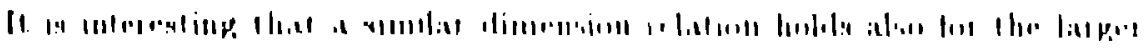

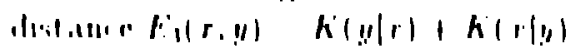


(7.2) Theorem Let $\boldsymbol{r}$ be a binary string. Threre is a posituve ronstant d surh that for all sufticiently large d. the number of binary string: $;$ wiph $E_{3}(r . y) \leq d$ is at most $2^{d} / d$ and at loibst $2^{1 /} / d^{2}$.

Proof The upper bound follows from the previous theorem since $E_{3} \geq E_{1}$. For the lower bound, cousider strings $y$ of the form $p e$ where $p$ is a , if-delimitiug program. For all such programs. $K(s \mid y) \stackrel{+}{<} 0$. sille $s$ can be roovered from $y$. Therefore $E_{3}(s, y) \doteq K(y \mid s)=K^{\prime}(p \mid s)$. Now just ats in the areument of the previous prouf. we oblain tho: lower bound 24 /it for the number of such st rings $p$ with $K^{\prime}(p \mid r) \leq d$.

For the distance $E_{3}$. for the number of strings of length n near a randon st ring $s$ of length $n$. (i.e. a string with $K(x)$ near $n$ ) the picture is a little different from that of distance $E_{l}$. In this distitner. "tongh guys have few neighbors". In particular, a t.umlom string $s$ of length $n$ has only aboule $2^{d, 2}$ s? inge of length $n$ within distance d, the following theorm describes a more general ituation.

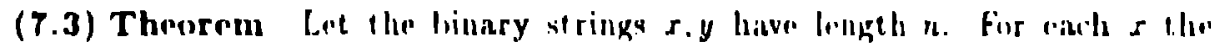
mumber of $y^{\prime} x$ sith that $E_{3}(r . y) \leq$ is is ?" with

$$
11:=\frac{n+a-k(s)}{2} \pm()(\log n) \text {. }
$$

while $n-h^{\prime}(s) \subseteq d$. Por $n-K^{*}(s) \because$ d wo have d - d t ()(logn).

Proof laet $k^{\prime}(s)=n-s(n)$. In the remainder of the pronf all (in)erenalitions

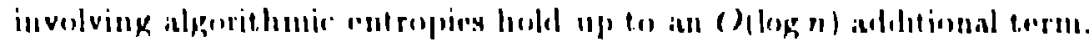

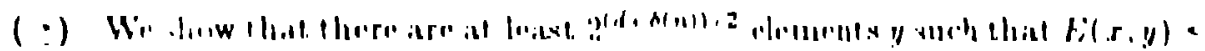

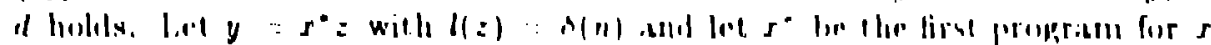

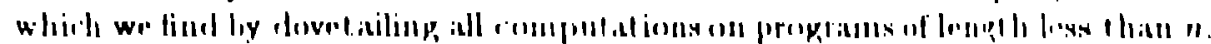

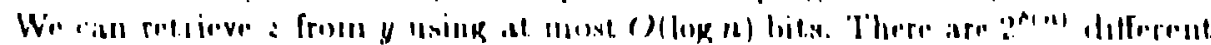

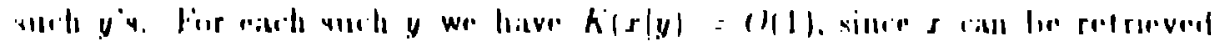

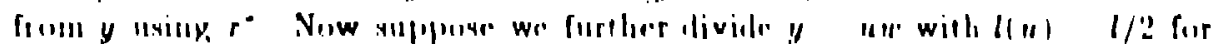

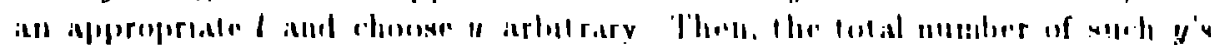

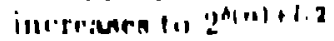

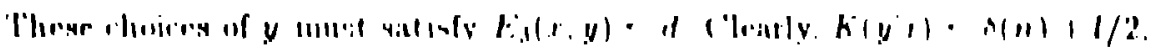

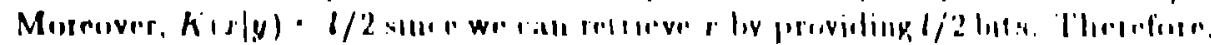

$$
k(r \mid y)|K(y \mid r) \cdot 1 /:+A(u)| l / ?
$$

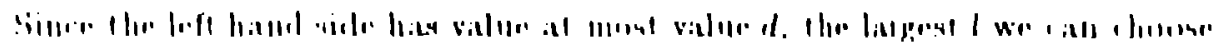

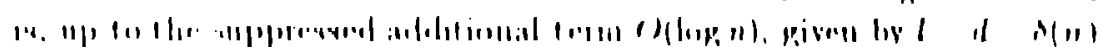

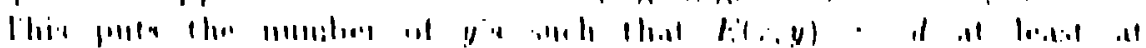
? 
(s) Assume, to the coutrary. that there a, at leatt $2^{(d+A \mid n+1 \cdot 2+c}$ plenente $y$ ild that $E_{3}(s, y) \leq d$ holds, with a: some large constant. Then. for some $y$,

$$
K(y \mid s) \geq \frac{d+\delta(n)}{2}+\cdots
$$

By assumption

$$
K(r)=n-\delta(n) . K(y) \leq n .
$$

By the aldition theorem 2.3 we tind

$$
n+\frac{d-d(n)}{2}+r \leq n+K(r \mid y)
$$

But this means that

$$
K(x \mid y) \geq \frac{d-\phi(n)}{2}+c
$$

which. by Ecpuations (7.f) and $(7.5)$, contraliets $K(r \mid y)+K(y \mid r) \leq d$.

It followe from our astimates out, that in overy set of low algorithmic entropy almost all elementes are far away frem ravh oflere in terms of the distance fo. Here. the algorithmic "nteroy $K^{\prime}(S)$ of a set is the longth of the shortest hinary prokram that enumeritien $S$ atul then hialts.

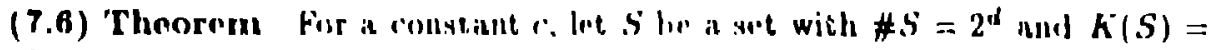

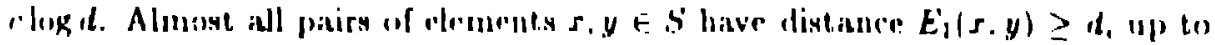
all alditive logarithmic torm.

The proof of this theorem is rasy. A similar st at ement ran be proved for the

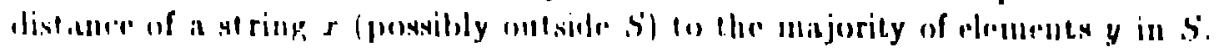

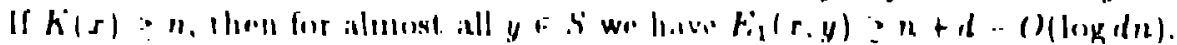

\section{A thermodynamic potentinl}

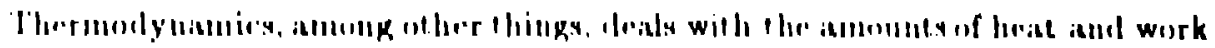

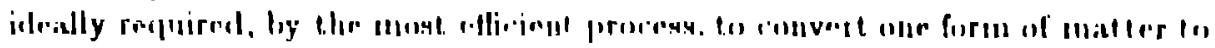

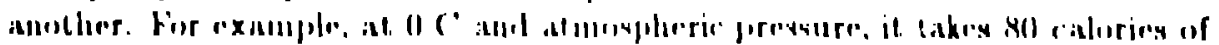

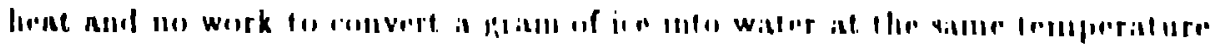

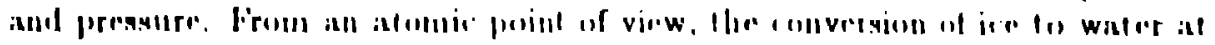

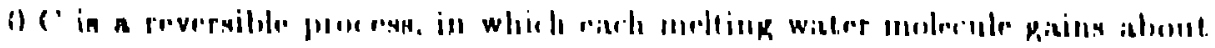

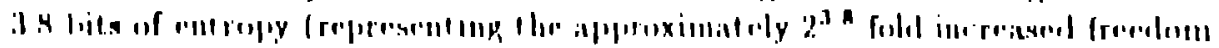

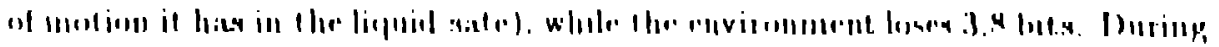

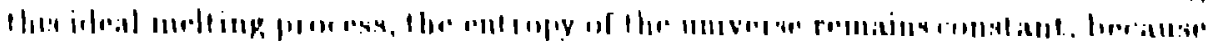

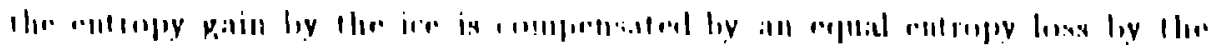

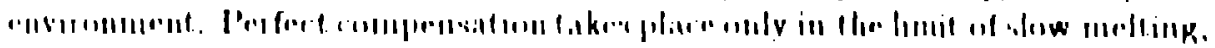

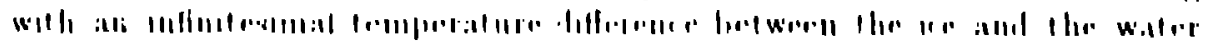


Rapid melting. e.g. when ior is dropped into hot water. is thermorlynamioally irreversible and inetficint, with the environment (the hot water) losing less rentropy than the ice gains. resulting in a net and irrodermable entropy increasio for the muverse as a whole.

Turning again to ideal reversible processes. the phtropy rhange in going from state $X$ to state $Y$ is an antisymmetrie fumetion of $X$ and $Y$ : thus. when water freezes at $0(\mathrm{C}$ hy the most efficient processs. it gives up 3.8 bits of entropy per molecele to the environment. When more than two states are involvod. the rutrop, changes are transitive: thus the entropy change per molecule of going from ice 10 water vilpor at $0 \mathrm{C}(+32.6$ bits) plus that for going from vapor tos liquid water (-28.8 bits) sum to the entropy change for going from ice to wator clirectly. Bucause of this antinymmetry and transitivity, entropy can be regareled its a thermonlynamir potential or state function. eich stiate has an ent ropy, and the entropy chisuge in going from slate $X$ to state $Y$ by the most efficient process is simply the entropy difference between states $X$ and $Y$ '.

Thermodynamic irleisy were first successfully applied to computation by Landauer. Acroriling to Landauer's principle [12.5. 17. 18. 6] an operation which

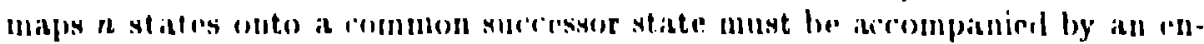

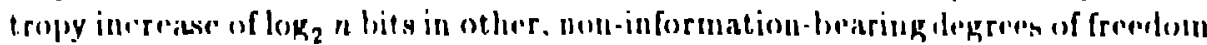
in the computer or its environment. At mom temperature, this is ropuivalent

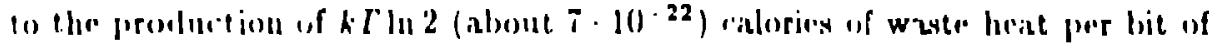
informattion distiralad.

Jandauer's priniciple follows from the fact that such a logically irreversibl.

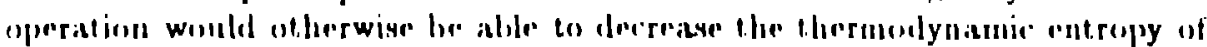

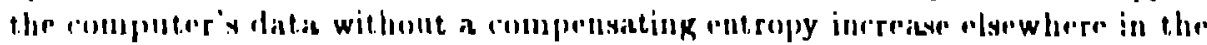
nniverse, lhereby violating the soromel liaw of thermenlynamics.

(onverse to landaner's principele is the fact that when as romputer lakes a

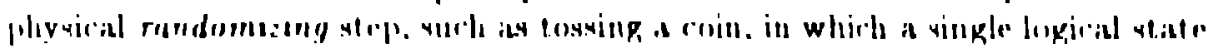

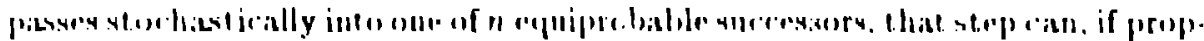

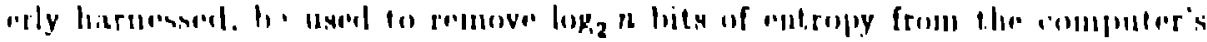

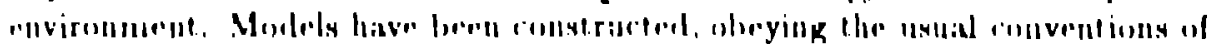

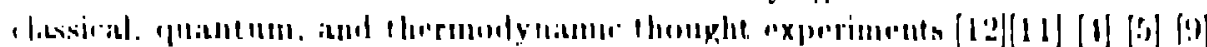

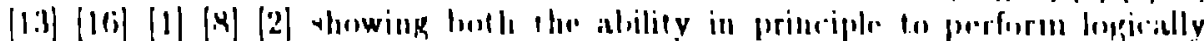

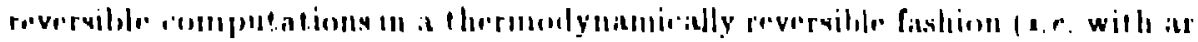

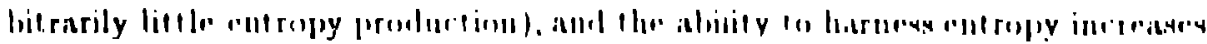

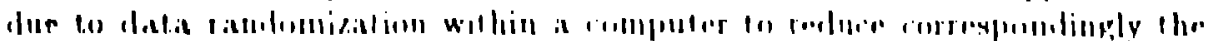
entropy of its environment.

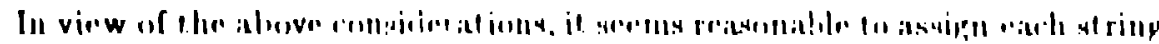

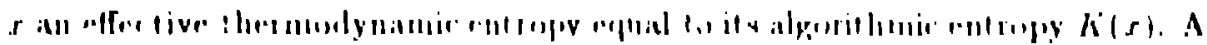

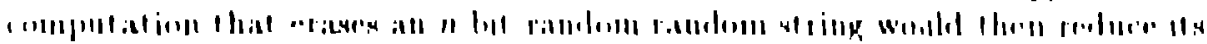

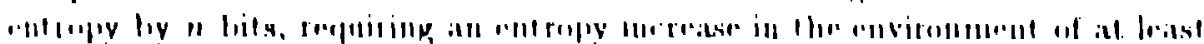

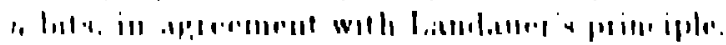

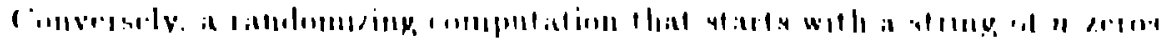

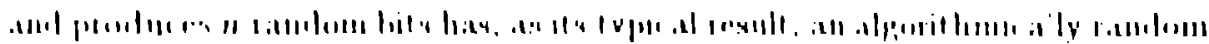


$n$-lit string $x$, t.e. one for which $K(s)=n$. By the ronverse of Limdancrs priniple. this randomizing computation is capable of removing up to $n$ bits of "nt ropy from the pnvironment, again in agrem ment with the iclentitication of the lhermodynamic and algorithmic: entropy.

What about computations that start with one random string $r$ and rind with another $y$ ? By the transitivity of entropy changey une is lod tos sily that the thermodynamic cost. i.e. the minimal entropy increase in the environment. of a transformation of $x$ into $y$, vhould be

$$
C(y \mid s)=K^{*}(x)-K^{-}(y) \text {. }
$$

berause the transformation of $s$ into $y$ could be timonght of as a two-step proress in which one first erases $r$, then allows y to be producol by randomiation. By the elementary properties of solf dolimiting programs, his ast. measure is transitive wiphin an additive constant. $C^{\prime}(y \mid s)$ : meisure of the theruobly namic cost of diate transformations.

$$
C^{\prime \prime}(y \mid r)=K(r \mid y)-K(y \mid r)
$$

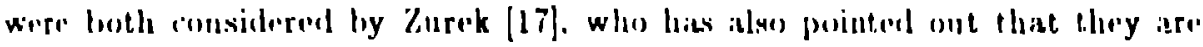

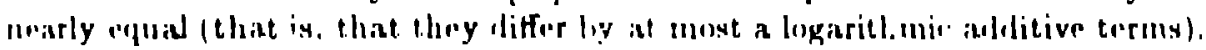
Here we mote that $("(y / s)$ is slightly non-tiansitive. For example, there exist

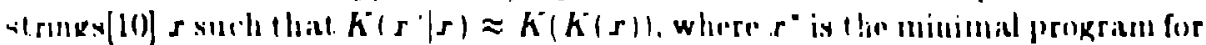

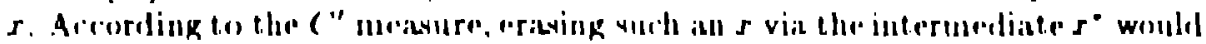

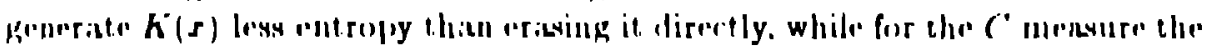

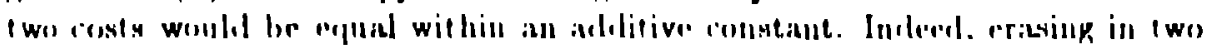

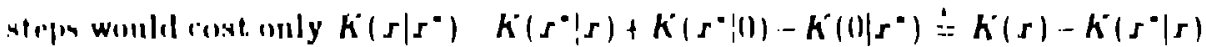

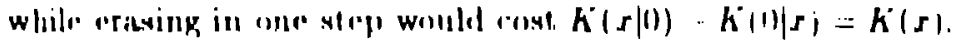

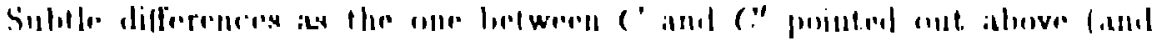

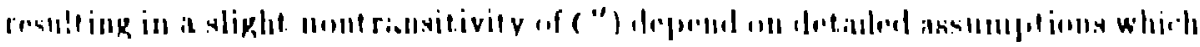

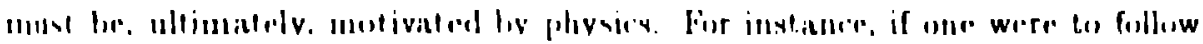

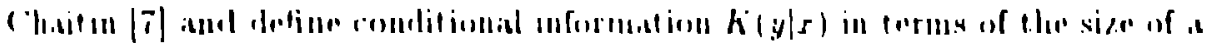

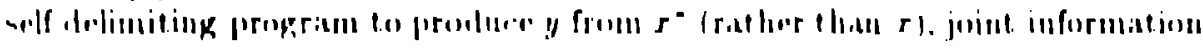
nomblid lie piven ilireetly by

$$
K(r, y) \quad h(r)+K(y, r) \text {. }
$$

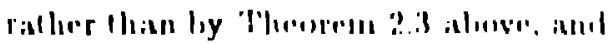

$$
(" ! ! n \mid r) \quad(1, y \mid \cdot r)
$$

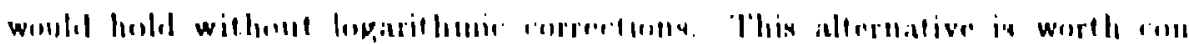

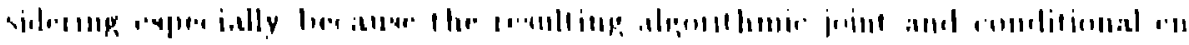

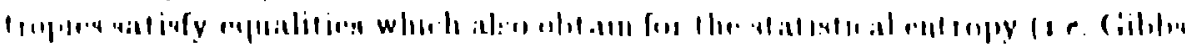

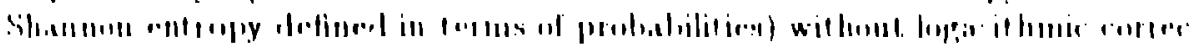

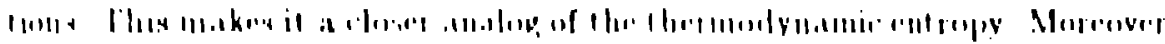

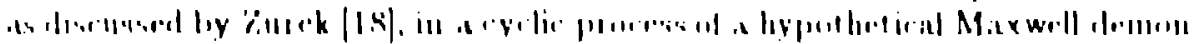

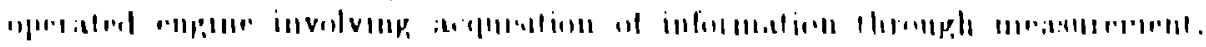


"xpansion. and subsequent erasures of the records compressond by reversible computation the optimal efficieary of the eycle could be assiured only by ansuming that the relevant minimal programs are already availes.

These remarks lead one to consider a more general issue of eut ropy changes in nonideal computations. Bennept[5] and especially Zurek[18] have considered the thermodynamics of an interligent demon or engine which has some "apacity (1) analyze and transform data $x$ before eribing ii. If the de nuon erisies a rambomlooking st ring. such at the ligits of $\pi$, without taking the troublo to umblerstanci it, it will commit a thermodynamically irreversible art. in which the entropy of the data is decreasid very little, while the entropy of the renvironment increases by a full $n$ bits. ()n the other hand, if the demon recognizes the redundancy in $\pi$. it can transform $\pi$ to an empty string by a reversible compntation. and thereby acomplish the" "rasture al very lithle thermorlynamic rost. Mure genarally. given unlimited time, a demon could approximate the semicomputable function $K(x)$ and so compress a string $x$ to size $K(s)$ before arasing it. But in limited time. the demon will not he able to compress $s$ so much, and will have M generate. more enteropy to get rid of it. 'This trideoff betwern speed and thermodynanic

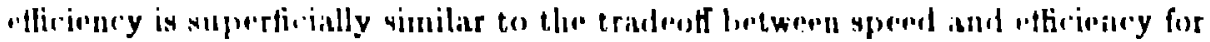
physiend proverssess such as melting. but the functional form of the tradeotf is

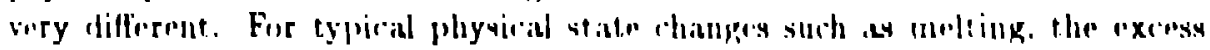

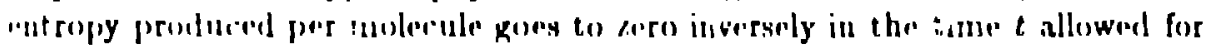

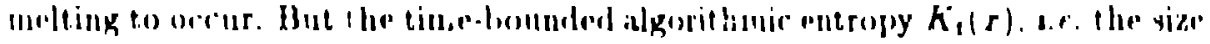

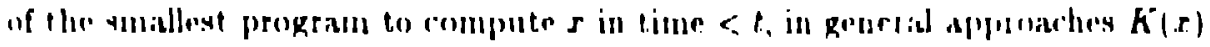
unly with uncomputable slowness ibs as function of $t$ and $r$.

\section{References}

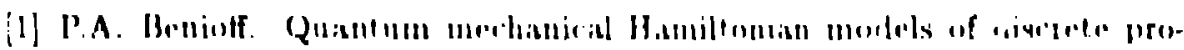

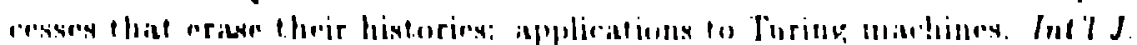

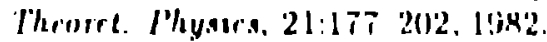

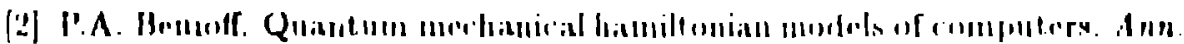

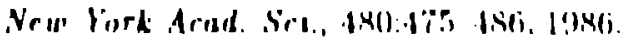

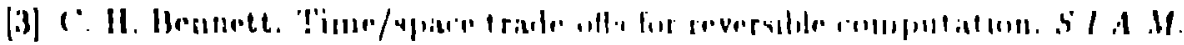

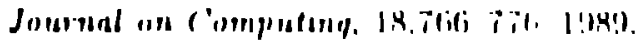

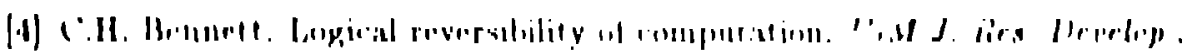
17.525, 5it2, 19\%is.

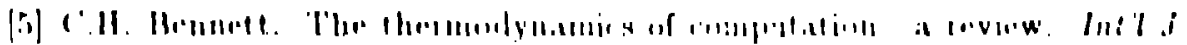

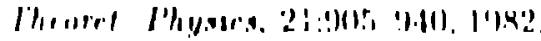


[6] C. M. Caves. W. G. Enruh and W. H. Zurek. Commont on quantitative limits on the ability of a Miuxwell Demon to extract work from hiat. Phys. Rev. Lett.. 65:1387. 1900.

[7] G. Chaitin. A throry of program size formally identical to information theory. J. Assoc. Comput. Mach., 22:320 341), 1975.

[8] R.P. Feyunan. Quantum mechanical computers. Optucs Veus. 11:11. 1985.

[O] E. Fredkin and T. Toffoli. Couservative logie. Intll J. Thenret. Physics. 21(3/4):219 253. 1982.

(10) P. Gács. On the symmetry of algorithmic information. Sompt Math. Doklady, 10:1477 1480, 197.4. ('orrertion, Ihid., 1511074). 1430.

[11] R.W. Keyes and H. Landiner. Minimal energy dissipation in logic. ID.M J. Res. Derelop., 14:152 15i. 1970.

[12] R. Landanre. Irreversilility and heat generition in the computing process. IB.K J. Res. Dorerlop.. pakes 1\$3 1:)1. July 1961.

[1:3] R. Landiuler. Int. J. Theor. Thy,.. 21:283. 1982

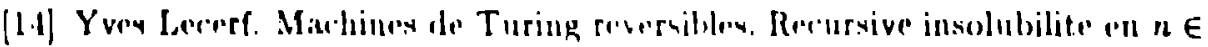

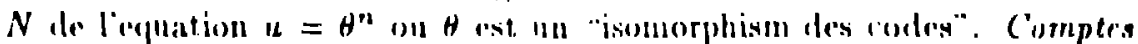
Rendus. 257:1597 26(10). 196.3.

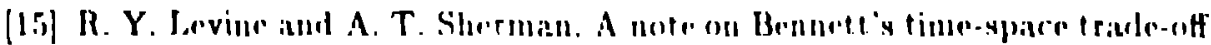

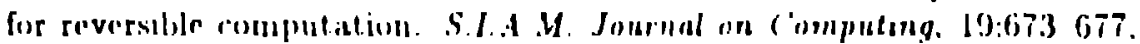
$1 !)(1)$.

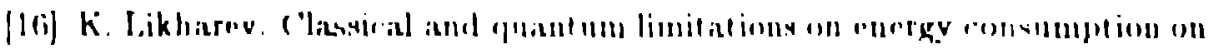

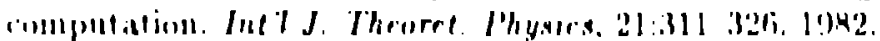

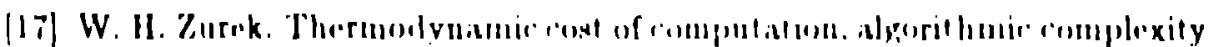

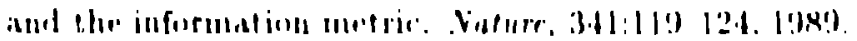

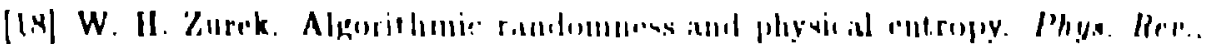
A.1():47:31 $\left.17.1,1,194^{\prime}\right)$

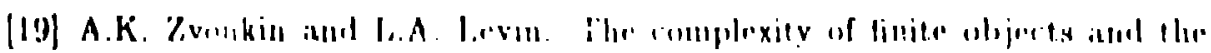

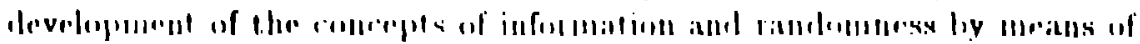

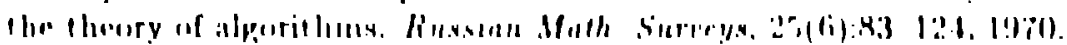

